government measures were less restrictive, due to the minimum RT index values recorded in Italy. Older age and lower count of weekly outings were associated with PTSD in SSc patients during the lockdown, whereas the count of weekly outings was lower than in $\mathrm{HC}$ during both the examined periods. The results of this study indicate that COVID-19 lockdown had a worse impact in SSc patients, where the fewer weekly outings may depend on their clinical condition and on a greater concern about their health ${ }^{6}$. These findings strengthen the World Scleroderma Foundation recommendations regarding care to the psychological frailty of SSc patients ${ }^{7}$.

REFERENCES:

[1] Wang C, Brain Behav Immun. 2020.

[2] Dubey S, Psychiatr Pol. 2020.

[3] Thombs BD, J Psychosom Res. 2020 Dec.

[4] https://covid19.infn.it/grafici/?chart=italia,rt,covidstat

[5] Weiss, D. S., \& Marmar, C. R. (1996). The Impact of Event Scale - Revised, Assessing. psychological trauma and PTSD (pp. 399-411).

[6] Orlandi M, Clin Rheumatol. 2020

[7] Matucci-Cerinic M, Ann Rheum Dis. 2020

Table 1. Descriptive analysis of study population: T0 (Time 0), T1 (Time 1), SD (Standard Deviation), IES-R (Impact of Event Scale-Revised).

\begin{tabular}{|c|c|c|}
\hline & SSc patient group & HS group \\
\hline Female:male ratio at T0 & $46: 7$ & $46: 7$ \\
\hline Mean age \pm SD at To & $59 \pm 12.8$ & $51 \pm 8.7$ \\
\hline IES-R $\geq 33$ score $n \%$ at TO & $26 / 45.6 \% *$ & $13 / 22.8 \%$ \\
\hline IES-R $\geq 33$ score $n \%$ at $T 1$ & $18 / 40.9 \%$ & $8 / 23.5 \%$ \\
\hline IES-R score at TO, median value [quartiles] & $31[19.5 ; 42.5]$ & $24[15.5 ; 32]$ \\
\hline IES-R score at T1, median value [quartiles] & $26[15.25 ; 38]$ & $26.5[20.75 ; 32.5]$ \\
\hline $\mathrm{N}^{\circ}$ of weekly outings at $\mathrm{TO}$, median value [quartiles] & $2[1 ; 3.5]$ & $4[2 ; 10]^{\star \star}$ \\
\hline $\mathrm{N}^{\circ}$ of weekly outings at $\mathrm{T} 1$, median value [quartiles] & $5[3 ; 6]$ & $14[6.75 ; 15]^{\star \star}$ \\
\hline
\end{tabular}

${ }^{*} p<0.046 ;{ }^{* *} p<0.001$

Disclosure of Interests: None declared.

DOI: 10.1136/annrheumdis-2021-eular.1266

\section{POS1186 1 EFFECT OF SOCIO-ECONOMIC STATUS AND EDUCATIONAL LEVEL ON COVID-19 OUTCOMES IN PATIENTS WITH RHEUMATIC DISEASES FROM ARGENTINA: DATA FROM THE SAR-COVID REGISTRY}

L. Sorrentino ${ }^{1}$, J. Rebak $^{1}$, F. Maldonado ${ }^{1}$, V. V. Castro Coello ${ }^{1}$, A. Brigante ${ }^{1}$, A. Hamaui ${ }^{1}$, D. Dubinsky ${ }^{1}$, R. Baez ${ }^{2}$, C. Pisoni ${ }^{2}$, C. Gobbi ${ }^{2}$, L. Carlevaris ${ }^{2}$, R. Tanten ${ }^{2}$, A. K. Cogo ${ }^{2}$, M. Delavega ${ }^{2}$, R. Perez Alamino², M. A. Lazaro², M. Pera ${ }^{2}$, S. I. Pineda Vidal' ${ }^{2}$ M. E. Calvo ${ }^{2}$, D. Guaglianone ${ }^{2}$, C. G. Alonso ${ }^{2}$ M. Guinsburg ${ }^{2}$, C. Retamozo ${ }^{2}$, C. Aeschlimann ${ }^{2}$, R. Quintana ${ }^{3}$, K. Roberts ${ }^{3}$ C. A. Isnardi ${ }^{3}$, G. Pons Estel ${ }^{3}$ on behalf of SAR-COVID Registry. ${ }^{1}$ Sanatorio Güemes, Department of Rheumatology, Ciudad Autónoma de Buenos Aires, Argentina; ${ }^{2}$ Argentine Society of Rheumatology, On behalf of SAR-COVID Registry, Ciudad Autónoma de Buenos Aires, Argentina; ${ }^{3}$ Argentine Society of Rheumatology, Research Unit - SAR-COVID Registry, Ciudad Autónoma de Buenos Aires, Argentina

Background: SARS-CoV-2 infection can present with a broad clinical spectrum, from asymptomatic to lethal. Different risk factors have been recognized. Socio-economic status and educational level may affect access to the healthcare system and therefore COVID-19 infection outcome.

Objectives: The aim of this study was to assess the association between socio-demographic status and educational level and SARS-CoV-2 outcomes, such as hospitalization, ICU admission, need for mechanical ventilation and death, in Argentinean patients with rheumatic diseases from the SAR-COVID Registry.

Methods: We performed a cross-sectional study of consecutive adult patients with rheumatic diseases and SARS-CoV-2 infection included in the multicentric Argentinean SAR-COVID Registry. The following variables were included: gender, ethnicity, age, health insurance, educational level (under or over 12 years of education), socio-economic level according to Graffar Scale in high, medium-high, medium, medium-low, low; underlying rheumatic disease, its duration and treatment at the time of infection.

SARS-CoV-2 infection outcomes were: hospitalization, admission to ICU, mechanical ventilation requirement and death.

Statistical analysis was performed using $\mathrm{Chi}^{2}$, Fisher, T-test, ANOVA.

Results: Five hundred and twenty-five patients were included, $422(80.4 \%)$ were female, with a mean age of 51.3 years (SD 15.2). Most of them were caucasians $(48 \%)$ or mestizos $(43 \%)$ and $96.8 \%$ lived in an urban environment. Almost half of the patients (47\%) were categorized as middle-class, $24 \%$ middle-high or high class, $21 \%$ middle-low or low. $48.4 \%$ of the patients were employed. Regarding educational level, $54 \%$ had more than 12 years of education.
The most prevalent rheumatic disease was Rheumatoid Arthritis (40.4\%), followed by Systemic Lupus Erythematosus (14.9\%), Sjögren (5.5\%) and Psoriatic Arthritis (5.5\%). Treatments used at the time of SARS-CoV-2 infection were corticosteroids (19\%), cs-DMARDs (49\%), and b- and ts-DMARDs (16\%).

Overall hospitalization frequency was 35\%, median hospital stay was 10 days (IQR 10 days), $11.6 \%$ were admitted to the ICU, 10\% required mechanical ventilation and the global mortality was $8 \%$.

Notably, patients with less than 12 years of education required mechanical ventilation more frequently than the more educated ones $(11.9 \%$ vs. $5.6 \%$ $p=0.026)$ and showed a higher mortality due to COVID-19 (9\% vs. $2.8 \%$, $p=0.0004$ )

Patients categorized as upper social classes (middle-high and high) were admitted to the hospital on a more frequent basis $(74.4 \%$ of cases), when compared with middle class $(64.4 \%)$ and middle-low and low class $(58 \%)(p=0.77)$. Median duration of hospitalization for the aforementioned groups was 12.5 (IQR 17.3), 10 (IQR 9) and 10.5 (IQR 9.3) days respectively ( $p=0.60)$.

Patients with health insurance were found to be hospitalized more frequently in comparison to those without insurance $(42.4 \%$ vs. $33.7 \%, p=0.14)$, but showed similar admission rates to the ICU (11.8\% vs. $12.8 \% ; p=0.78)$, need for mechanical ventilation $(10.7 \%$ vs. $8.7 \%$; $p=0.70)$ and mortality $(7.1 \%$ vs. $6.5 \% ; p=0.99$ )

Caucasian patients had fewer hospital admissions when compared against other ethnicities (mestizos mostly) (26.1\% vs. $43.4 \%$; p<0.0001), but showed no statistically significant difference in need for mechanical ventilation $10.3 \%$ vs. $9.9 \%$ $(p=0.99)$ or mortality $8.7 \%$ vs. $5.1 \%(p=0.15)$

Conclusion: Patients with lower educational level needed twice the frequency of mechanical ventilation, and showed thrice the mortality than those with more than 12 years of education.

Albeit patients in upper social stratus and those with health insurance were admitted to the hospital in a more frequent manner, no statistically significan differences were found regarding the need for $\mathrm{ICU}$, mechanical ventilation or mortality.

Caucasians were hospitalized less frequently than mestizos, but had no significant differences in the other measured outcomes.

Disclosure of Interests: Laura Sorrentino Grant/research support from: Unrestricted grants: Pfizer, Abbvie, Elea Phoenix. None of them have access to patient data., Jonathan Rebak Grant/research support from: Unrestricted grants: Pfizer, Abbvie, Elea Phoenix. None of them have access to patien data., Federico Maldonado Grant/research support from: Unrestricted grants: Pfizer, Abbvie, Elea Phoenix. None of them have access to patien data., Vanessa Viviana Castro Coello Grant/research support from: Unrestricted grants: Pfizer, Abbvie, Elea Phoenix. None of them have access to patient data., Alejandro Brigante Grant/research support from: Unrestricted grants: Pfizer, Abbvie, Elea Phoenix. None of them have access to patient data., Adriana Hamaui Grant/research support from: Unrestricted grants: Pfizer, Abbvie, Elea Phoenix. None of them have access to patient data., Diana Dubinsky Grant/research support from: Unrestricted grants: Pfizer Abbvie, Elea Phoenix. None of them have access to patient data., Roberto Baez Grant/research support from: Unrestricted grants: Pfizer, Abbvie, Elea Phoenix. None of them have access to patient data., Cecilia Pisoni Grant/ research support from: Unrestricted grants: Pfizer, Abbvie, Elea Phoenix. None of them have access to patient data., Carla Gobbi Grant/research support from: Unrestricted grants: Pfizer, Abbvie, Elea Phoenix. None of them have access to patient data., Leandro Carlevaris Grant/research support from: Unrestricted grants: Pfizer, Abbvie, Elea Phoenix. None of them have access to patient data., Romina Tanten Grant/research support from: Unrestricted grants: Pfizer, Abbvie, Elea Phoenix. None of them have access to patient data., Adriana Karina Cogo Grant/research support from: Unrestricted grants: Pfizer, Abbvie, Elea Phoenix. None of them have access to patien data., Maria DeLaVega Grant/research support from: Unrestricted grants: Pfizer, Abbvie, Elea Phoenix. None of them have access to patient data. Rodolfo Perez Alamino Grant/research support from: Unrestricted grants: Pfizer, Abbvie, Elea Phoenix. None of them have access to patient data. Maria Alicia Lazaro Grant/research support from: Unrestricted grants: Pfizer, Abbvie, Elea Phoenix. None of them have access to patient data., Mariana Pera Grant/research support from: Unrestricted grants: Pfizer, Abbvie, Elea Phoenix. None of them have access to patient data., Susana Isabel Pineda Vidal Grant/research support from: Unrestricted grants: Pfizer, Abbvie, Elea Phoenix. None of them have access to patient data., Maria Elena Calvo Grant/research support from: Unrestricted grants: Pfizer, Abbvie, Elea Phoenix. None of them have access to patient data., Debora Guaglianone Grant/ research support from: Unrestricted grants: Pfizer, Abbvie, Elea Phoenix. None of them have access to patient data., Carla G Alonso Grant/research support from: Unrestricted grants: Pfizer, Abbvie, Elea Phoenix. None of them have access to patient data., Mara Guinsburg Grant/research support from: Unrestricted grants: Pfizer, Abbvie, Elea Phoenix. None of them have access to patient data., Cinthya Retamozo Grant/research support from: Unrestricted 
grants: Pfizer, Abbvie, Elea Phoenix. None of them have access to patient data., Carolina Aeschlimann Grant/research support from: Unrestricted grants: Pfizer, Abbvie, Elea Phoenix. None of them have access to patient data., Rosana Quintana Grant/research support from: Unrestricted grants: Pfizer, Abbvie, Elea Phoenix. None of them have access to patient data., Karen Roberts Grant/research support from: Unrestricted grants: Pfizer, Abbvie, Elea Phoenix. None of them have access to patient data., Carolina Ayelen Isnardi Grant/research support from: Unrestricted grants: Pfizer, Abbvie, Elea Phoenix. None of them have access to patient data., Guillermo Pons Estel Grant/research support from: Unrestricted grants: Pfizer, Abbvie, Elea Phoenix. None of them have access to patient data.

DOI: 10.1136/annrheumdis-2021-eular.1294

\section{POS1187 WILLINGNESS TO GET THE COVID-19 VACCINE AMONG PATIENTS WITH RHEUMATIC DISEASES, HEALTH WORKERS AND GENERAL POPULATION}

B. Yurttas ${ }^{1}$, B. C. Poyraz ${ }^{2}$, N. Süt ${ }^{3}$, A. Ozdede ${ }^{1}$, M. Oztas ${ }^{1}$, Ö. F. Tabak', V. Hamuryudan ${ }^{1}$, E. Seyahi ${ }^{1} .{ }^{1} /$ stanbul University- Cerrahpasa, Cerrahpasa Medical Faculty, Department of Internal Medicine, Division of Rheumatology, Istanbul, Turkey; ${ }^{2}$ Istanbul University- Cerrahpasa, Cerrahpasa Medical Faculty, Department of Psychiatry, Division of Geropsychiatry, Istanbul, Turkey; ${ }^{3}$ Trakya University Medical Faculty, Department of Biostatistics and Medical Informatics, Edirne, Turkey; ${ }^{4}$ Istanbul University-Cerrahpasa, Cerrahpasa Medical Faculty, Department of Infectious Diseases and Clinical Microbiology, Istanbul, Turkey

Background: As of January 2021 the COVID-19 pandemic has been responsible for more than 2.2 million deaths worldwide (1). Potential vaccines against COVID-19 have been developed swiftly and vaccination programs were started in many countries. Turkey agreed to use inactivated vaccine candidate, 'CoronaVac' produced by Chinese biopharmaceutical company (3). Many of our patients having a rheumatic diseases (RD) call us for permission to get vaccination, while some express their concerns about the efficacy and safety issues.

Objectives: We therefore assessed the willingness to get vaccination among patients with RD compared to health workers and a sample from general population.

Methods: A web-based questionnaire study was conducted in a cross-sectional design in 3 groups of participants: 1. patients with RD, 2. hospital workers and 3. General population. The questionnaire sought socio-demographic variables, COVID-19 related risk factors, willingness to get vaccination, and concerns and thoughts about vaccine. COVID-19 related anxiety (CAS) was also evaluated through the questionnaire.

Results: We studied in total $732(258 \mathrm{M} / 474 \mathrm{~F})$ patients with RD, $320(88 \mathrm{M} /$ $232 \mathrm{~F})$ hospital workers and $763(258 \mathrm{M} / 505 \mathrm{~F})$ individuals representing general population. Patients with RD were significantly older and less educated and spent less time using social media compared to both control groups (Table 1). CAS scores were similar between the study groups. Of the patients with RD, $29.2 \%$ were willing to be vaccinated, $19 \%$ were unwilling and $51.8 \%$ were undecided. These were similar among the general population $34.6 \%$, $23.3 \%$ and $42.1 \%$, respectively), whereas hospital workers were significantly more willing $(52.5 \%, 20.9 \%$ and $26.6 \%$, respectively) ( $<<0.0001)$. About a third in each group thought that vaccination should be obligatory. The major concerns associated with vaccine were fear from side effects, unknown scientific results and lack of confidence. Being male, older age, working in a hospital and increased anxiety levels were found to be independently associated with willingness.

Conclusion: Only about one third of the patients with RD were willing to get vaccination, which was somewhat similar to that observed among the general population. This could be due to rushed vaccine development as well as negative news on vaccines on the social media. Our study also reveals that, after almost one year after the pandemic, about $95 \%$ in all study groups did not express dysfunctional anxiety related with COVID-19.

REFERENCES:

[1] https://covid19.who.int/

[2] https://www.bloomberg.com/news/articles/2020-12-26/ turkey-signs-accord-with-biontech-for-coronavirus-vaccine
Table 1. Socio-demographic and COVID-19 associated variables, anxiety scores and willingness to get vaccination

\begin{tabular}{|c|c|c|c|c|}
\hline & $\begin{array}{c}\text { Patients with } \\
\text { RD } \\
(n=732)\end{array}$ & $\begin{array}{l}\text { Hospital } \\
\text { workers } \\
(n=320)\end{array}$ & $\begin{array}{l}\text { General } \\
\text { population } \\
(n=763)\end{array}$ & $P$ \\
\hline Male/ Female, $\mathrm{n}$ & $258 / 474$ & 88/232 & $258 / 505$ & 0.045 \\
\hline Age, mean $\pm S D$, years & $42.8 \pm 11.6$ & $37.0 \pm 10.0$ & $40.8 \pm 12.0$ & $<0.001$ \\
\hline Primary/middle school education, n (\%) & $225(30.7)$ & $6(1.9)$ & $28(3.7)$ & $<0.001$ \\
\hline $\begin{array}{l}\leq 1 \text { hour daily spent using social media, } \\
n(\%)\end{array}$ & $270(36.9)$ & $100(31.3)$ & $192(25.2)$ & $<0.0001$ \\
\hline $\begin{array}{l}\text { COVID-19 related anxiety, total score, } \\
\text { mean } \pm \text { SD }\end{array}$ & $1.62 \pm 3.03$ & $1.81 \pm 2.64$ & $1.55 \pm 2.71$ & 0.389 \\
\hline $\begin{array}{l}\text { COVID- } 19 \text { related anxiety, cut off value of } \\
\geq 9, n(\%)\end{array}$ & $36(5.1)$ & $13(4.2)$ & $29(4.0)$ & 0.626 \\
\hline \multicolumn{4}{|c|}{ COVID-19 diagnosis in the participant $(\mathrm{n} \%)$} & $<0.0001$ \\
\hline Yes & $104(14.2)$ & $69(21.6)$ & $70(9.2)$ & \\
\hline No & $617(84.3)$ & $248(77.5)$ & $687(90.0)$ & \\
\hline Unsure & $11(1.5)$ & $3(0.9)$ & $6(0.8)$ & \\
\hline \multicolumn{4}{|c|}{ COVID-19 diagnosis among the household or close friends, $\mathrm{n}(\%)$} & $<0.0001$ \\
\hline Yes & $460(62.8)$ & $244(76.3)$ & $435(57.0)$ & \\
\hline No & $254(34.7)$ & $76(23.8)$ & 317 (41.5) & \\
\hline Unsure & $18(2.5)$ & 0 & $11(1.4)$ & \\
\hline Presence of any comorbid disease, $n(\%)$ & $304(41.5)$ & 67 (20.9) & $181(23.7)$ & $<0.0001$ \\
\hline History of psychiatric disorder, $\mathrm{n}(\%)$ & $177(24.2)$ & $51(15.9)$ & $110(14.4)$ & $<0.0001$ \\
\hline \multicolumn{4}{|l|}{ Willingness to get vaccination ( $\mathrm{n} \%)$} & $<0.0001$ \\
\hline Yes & $214(29.2)$ & $168(52.5)$ & $264(34.6)$ & \\
\hline No & $139(19.0)$ & $67(20.9)$ & $178(23.3)$ & \\
\hline Unsure & $379(51.8)$ & $85(26.6)$ & $321(42.1)$ & \\
\hline \multicolumn{4}{|c|}{ Do you think that vaccination should be obligatory? n (\%) } & 0.003 \\
\hline Yes & $216(29.5)$ & $113(35.3)$ & $207(27.1)$ & \\
\hline No & $277(37.8)$ & $136(42.5)$ & $331(43.4)$ & \\
\hline Unsure & $239(32.7)$ & $71(22.2)$ & $225(29.5)$ & \\
\hline
\end{tabular}

Disclosure of Interests: None declared.

DOI: 10.1136/annrheumdis-2021-eular. 1435

\begin{tabular}{l|l}
\hline POS1188 & COVID-19 IN PATIENTS WITH RHEUMATIC DISEASES: \\
COMPARISON OF DATA FROM THE ARGENTINE \\
REGISTRY (SAR-COVID), WITH THE LATIN AMERICAN \\
AND GLOBAL REGISTRY (GLOBAL RHEUMATOLOGY \\
ALLIANCE)
\end{tabular}

A. A. Reyes ${ }^{1}$, G. Alle ${ }^{1}$, R. Tanten ${ }^{1}$, M. Scolnik ${ }^{1}$, E. Soriano ${ }^{1}$, G. Berbotto ${ }^{2}$, M. $\mathrm{Haye}^{2}$, M. J. Gamba ${ }^{2}$, R. Nieto ${ }^{2}$, M. García ${ }^{2}$, V. Savio², L. Gonzalez Lucero², P. Alba ${ }^{2}$, L. Takashima ${ }^{2}$, F. Risueño ${ }^{2}$, L. Casalla ${ }^{2}$, N. Cucchiaro² ${ }^{2}$ A. Bertoli ${ }^{2}$, S. Porta ${ }^{2}$, C. Maldini ${ }^{2}$, R. Gallo ${ }^{2}$, C. Goizueta ${ }^{2}$, E. Picco ${ }^{2}$, R. Quintana ${ }^{3}$, K. Roberts ${ }^{3}$, C. A. Isnardi ${ }^{3}$, G. Pons-Estel ${ }^{3}$ on behalf of SAR-COVID Registry ${ }^{1}$ Hospital Italiano de Buenos Aires, Reumatologia, Buenos Aires, Argentina; ${ }^{2}$ On behalf of SAR-COVID Registry, On behalf of SAR-COVID Registry, Buenos Aires, Argentina; ${ }^{3}$ Argentine Society of Rheumatology - Research Unit - SARCOVID Registry, Argentine Society of Rheumatology - Research Unit - SARCOVID Registry, Buenos Aires, Argentina

Background: SARS CoV-2 infection has recently burst onto the global scene and the knowledge of the course of this infection in patients with rheumatic diseases receiving immunomodulatory treatment is still insufficient. The Argentine Society of Rheumatology (SAR) designed a national registry called SAR-COVID in order to get to assess our reality.

Objectives: To identify the particular characteristics of patients with rheumatic diseases and COVID-19 in Argentina (SAR-COVID Registry), and to compare them with the data reported at the Latin American and Global level (Global International Alliance Rheum-COVID Registry).

Methods: A national, multicenter, prospective and observational registry was carried out. Patients older than 18 years, with a diagnosis of rheumatic disease and SARS-CoV-2 infection by PCR or serology, were included between August 13, 2020 and January 17, 2021. Demographic data, underlying rheumatic disease (activity of the disease, current treatment), comorbidities, clinical-laboratory characteristics of the SARS-CoV-2 infection, as well as received treatments (pharmacological, oxygen therapy / ventilatory support) and outcomes (hospitalization, mortality) were recorded. The characteristics of the 